\title{
REVIEW I Mozlandia: Morrissey Fans in the Borderlands
}

\author{
Melissa Mora Hidalgo \\ London: Headpress, 2016 \\ ISBN: 9781909394421 (PB) \\ Nicholas P. Greco \\ Providence University College \\ nicholas.greco@prov.ca
}

The love for the English singer Morrissey on the part of the Mexican immigrant population in California is not anything new for academics to study. A quick Internet search brings up popular press articles from the early 2000s that focus on Morrissey's popularity with Latinas and Latinos. On the discussion forums of the Morrissey fan site, Morrissey-Solo, users mention that Morrissey has been popular with such communities since at least the early 1990s. Melissa Mora Hidalgo's discussion of various facets of fan culture works to codify and exemplify what has been going on in Morrissey fan circles for years. Her book is useful for those interested in the study of celebrity, and in particular, in the study of fan practice. She explores the importance of physical sites, karaoke, tribute bands, and the imagined community that gathers to listen to the radio, as well as poetry and stage plays, all influenced by Morrissey. What makes her book-length study of fan practice unique is the focus on Latino/a immigrant communities (and their offspring) in Los Angeles and surrounding areas.

This book might be difficult for those who are used to purely academic tomes. Hidalgo considers the book a mix of stories, notes, diary entries, and scholarly inquiry: "The book mixes academic analysis with fanecdotes (fan anecdotes)" (26). Such colloquial language would be playful for some but bristling for others. Academics are no strangers to the fabrication of new terms, but Hidalgo sounds at times to be more sensationalist than scholarly with her continued forays into "Moz Angeles". Hidalgo mixes Morrissey lyrics into her prose, which serve as signs that show her loyalty to Morrissey and fellow Morrissey fans. To academics, though, this seems more like useless novelty, more cute than pragmatic.

This is not to say that there is nothing of worth in this relatively short book, though. Rather, it fills a hole for a truly fan-inspired work on celebrity. Hidalgo deftly places herself into the community that she documents. Implicitly, she is inquiring after her own fan experience, and almost literally mapping out the ways in which she manifests or plays out her desires for the English singer. 
Hidalgo embarks on a walking tour of Los Angeles landmarks that have some connection with Morrissey. What should be a cultural geography seems more an exercise in fan one-upmanship during which she demonstrates how much she knows about Morrissey's Los Angeles, and how close she is to the hallowed ground upon which he stepped. The sites and sights might serve another purpose: to demonstrate how a city can be remapped - or how a city's streets and places can take on a new definition, with new arteries of meaning and connections with people. This is really the interesting thing that Hidalgo is showing the reader, but the reader must first get through the fan-tourist discourse that seems to be at the forefront. The maps that are described in the book are meant to show where various events happened: the events contribute to "a living, shifting, and layered image of a particular brand of Morrissey fandom expressed in Los Angeles" (59).

In a particularly engaging section on what Hidalgo calls MorrisseyOke, - a form of the popular pastime of karaoke during which a participant sings (sometimes badly) in front of others in a bar or restaurant, often to terrible instrumental renditions of popular songs - she describes the scene at a local event during which a newcomer begins to sing the popular Smiths song "This Charming Man". But instead of singing in English, the woman sings the song in Japanese. Hidalgo suggests that this is a moment in which the singer claims a place or a sense of space, a reclamation of a piece of Los Angeles history, which is the territory of Japanese immigrants as much as it is the territory for Mexican immigrants. She writes that the performance "exemplifies the kind of signature MorrisseyOke moment for which we keep coming back: to celebrate the diversity of our fan expressions and, while we're at it, build community in a rapidly changing neighbourhood" (68). The change from the expected English to Japanese can be interpreted as a much more powerful moment, though: it is a moment of code switching in which the expected language is queered, thus displaying a compelling moment of transgression while being accepted within the constraints of the MorrisseyOke performance. Hidalgo, however, makes an alternate observation that the performance speaks to cultural and ethnic difference and the reclamation of place and space, which seems a less satisfying reading. Hidalgo recognizes the space as such later when she writes, "These are transgressive spaces in which desires are fulfilled, social norms are challenged, and new ways of being are imagined and lived out, if only for the length of a song, if only once a month at MorrisseyOke" (81).

That said, her analysis of the Boyle Heights neighbourhood and the problematic place that MorrisseyOke has within it is compelling and useful. Hidalgo suggests that the MorrisseyOke events demonstrate the tensions inherent in an event for relatively affluent immigrant communities (she uses the term gentefication) who have returned to the neighbourhood to which their parents immigrated, at the expense of younger, less affluent immigrants (72). And earlier in the section on MorrisseyOke, Hidalgo draws from Stephen Royce Giddens (2006) for karaoke as the "presentation of the self as karaoke life" (64), an interesting and useful idea for further work on the particular performance practice.

Hidalgo places the fascination with Morrissey by Latino/a communities in what George Lipsitz calls "the long fetch" (2007: vii-xii), that is, within a much longer history of popular music in California and its adoption by the first waves of Mexican immigrants and subsequent adoption by their English-speaking children. This is a revelation: most of the popular press coverage of the Latino/a fascination with Morrissey sees it as a curiosity. Hidalgo shows that it is reasonable, and almost inevitable.

The book attempts to straddle the worlds of academia and fan culture, and to be attractive to both. In its quest to be both fan-accessible (and the text explicitly 
plays to fans by referring to "our man [Morrissey]" (80), and by including references to lyrics throughout) and academically rigorous, it leaves academics feeling uneasy. It is not that the moments of true academic engagement are not worth the read, but rather the fan language throughout makes the book seem uneven. But one reader's perception of unevenness is another's sense of variety and novelty. The competing tones of the book reflect and echo the subject matter: Hidalgo is deftly trying to manage a community that is both Latino/a and American, who are attaching themselves to someone who is not them: white, English, wealthy. Hidalgo's book sits in that Latino/a in-betweenness that she identifies in the poetry of Vickie Vértiz.

Hidalgo's book is an important (and encouraging) reminder for scholars studying celebrity and popular music that there are still those who are highly invested (at the ground level, so to speak) in texts that are often the subject of analysis and academic rigour. Scholars need to be sensitive to this fact, and to understand anew that performers like Morrissey, in which so many find identity, can be powerful elements that contribute to people's self-actualization.

\section{References}

Lipsitz, G. 2007. Footsteps in the Dark: The Hidden Histories of Popular Music. Minneapolis: University of Minnesota Press.

Royce Giddens, S. 2006. "Singing Otherwise: Karaoke, Representation, and Practice." Studies in Popular Culture 28 (3): 93-109. 